\title{
A COBERTURA JORNALÍSTICA SOBRE O FEMINISMO BRASILEIRO (192I A 20|6): RELAÇÃO DE PÚBLICO E PRIVADO NA NARRATIVA SOBRE O ATIVISMO
}

\author{
The journalistic coverage about Brazilian feminism (I92I to 2016): public and \\ private relationship in the narrative about activism
}

Rayza Sarmento'

\begin{abstract}
Resumo
Este trabalho analisa a cobertura sobre o movimento feminista brasileiro no jornal Folha de São Paulo, entre os anos de 1921 a 2016, a partir de uma amostra com 579 textos, com o recorte temporal em três períodos distintos (1921-1959; 1960-1989; 1990-2016), a partir das ondas da historiografia feminista. Metodologicamente, empregamos a análise qualitativa de enquadramento, discutindo como a relação entre público versus privado, central na produção da teoria política feminista, pode colaborar para o entendimento de narrativas midiáticas sobre questões de gênero, em especial acerca do ativismo feminista. Os enquadramentos encontrados nos textos do periódico apontam, no primeiro período temporal, para um isolamento das atrizes feministas ao privado e também para processo de concessão masculina à entrada delas no público. No segundo momento, o enquadramento proeminente é da intersecção entre as duas esferas. No terceiro período temporal foram identificados enquadramentos de desnaturalização e re-naturalização acerca da relação entre as arenas.
\end{abstract}

Palavras-Chave: Feminismo; Jornalismo; Estudos feministas de mídia.

\begin{abstract}
This paper analyzes the coverage of the Brazilian feminist movement in the Folha de São Paulo, from 1921 to 2016, based on a sample of 579 texts, with a time cut in three different periods (1921-1959, 1960-1989, 1990-2016), from the waves of feminist historiography. Methodologically, we use the qualitative framework analysis, discussing how the relationship between public versus private, central to the production of feminist political theory, can contribute to the understanding of media narratives on gender issues, especially about feminist activism. The frameworks found in the texts of the journal indicate, in the first period of time, for the isolation of the feminist actresses from the private one and also for the process of masculine concession to the entrance of them in the public. In the second moment, the prominent framing is of the intersection between the two spheres. In the third temporal period, denaturalization and re-naturalization frameworks were identified on the relationship between arenas.
\end{abstract}

Keywords: Feminism; Journalism; Feminist media studies.

\footnotetext{
1 Professora Adjunta do Departamento de Ciências Sociais da Universidade Federal de Viçosa (UFV). Doutora em Ciência Política pela Universidade Federal de Minas Gerais (UFMG). Contato: rayzasarmento@gmail.com Cidade: Viçosa (MG).
} 


\section{Introdução}

A narrativa midiática sobre o movimento feminista em diferentes contextos geográficos tem se constituído como um caminho dos chamados estudos feministas de mídia (feminist media studies) (BARKER-PLUMMER, 2010; HIGH-PIPPER, 2005; LIND E SALO, 2002; MENDES, 2011A; NORTH, 2009; SARMENTO, 2018). A observação de como o ativismo feminista aparece nas esferas ampliadas de visibilidade, em especial no jornalismo, é uma forma importante de identificar a "identidade pública" (VAN ZOONEN, 1992) ou a "memória popular" sobre o movimento (SHERIDAN et al., 2006), colaborando para compreender reflexões, mitos e preconceitos que circulam publicamente.

Este trabalho, fruto de uma tese de doutorado, tem por objetivo mostrar quais foram os quadros de sentido sobre o feminismo brasileiro disponíveis em um exemplar da imprensa nacional (jornal Folha de S.Paulo), a partir de uma pesquisa entre 1921 e 2016, estendida temporalmente a fim de abarcar diferentes momentos do movimento. Para a análise, nos valemos da relação entre público versus privado, fundamental para os debates politicos feministas, como categoria para entender como se deu a narrativa acerca do ativismo. O trabalho está dividido em três partes, além desta breve introdução: a) a apresentação sucinta do debate entre público versus privado na teoria política feminista; b) a operacionalização metodológica e análise dos dados da cobertura jornalística sobre o feminismo a partir dessas categorias; e as c) considerações finais.

\section{Público x privado: um debate fundamental para os feminismos}

A relação público versus privado é questão fundante da teoria feminista. Ela ilumina como espaços, arenas e comportamentos assentam padrões de desigualdade de gênero. Por isso, para a análise da visibilidade do movimento feminista brasileiro na grande imprensa, optamos por trabalhar essa relação como uma categoria ${ }^{2}$, a fim de entender quais enquadramento sobre público versus privado estão visiveis nos textos.

$\mathrm{Na}$ teoria politica feminista, essa relação é lida de formas muito variadas. Uma primeira leitura vai junto ao enfrentamento da própria noção

\footnotetext{
$2 \mathrm{Na}$ tese de doutorado (Sarmento, 2017), defendemos também que é necessário observar o feminismo nas notícias a partir de outra categoria central para a teoria feminista: a noção de sujeito.
} 
liberal que separou as duas esferas, com a crítica principal de que a construção do homem público, e dos processos morais e políticos ensejados por ela, se deu a partir da marginalização das mulheres ao privado. Aqui aparecem obras como a de Carole Pateman e o seu "O Contrato Sexual" (1993). Pateman (1993) mostra como o entendimento canônico de um contrato social, uma ficção que inaugura a sociedade, ignora as relações sexuais hierárquicas que a definem. Ao mostrar o entendimento dos filósofos modernos como Rousseau, Locke e Mill sobre essa relação contratual, Pateman (1993) descortina também o imbricamento entre o poder dos homens na esfera tida como privada e a construção das economias capitalistas. "As aptidões que permitem aos homens, mas não às mulheres, serem trabalhadores são as mesmas capacidades masculinas exigidas para se ser um indivíduo, um marido e um chefe de família” (PATEMAN, 1993, p. 63).

Sylvia Walby (1990) também se alinha a essa ideia de estrita relação entre as duas esferas, ao defender a existência de um sistema patriarcal, não fixo ou a-histórico, incrustrado em estruturas como as de trabalho, Estado e instituições simbólico-culturais, tais como mídia, igrejas e escolas. O transbordamento da submissão dos espaços domésticos para arenas públicas, segundo Walby (1990, p. 178, tradução nossa), é evidente e "as instituições consideradas convencionalmente como parte do domínio público são centrais na manutenção do patriarcado". No patriarcado público, a dominação não atua de forma individual especificamente, com a submissão de uma mulher a um homem, mas constrangendo as possibilidades de ação das mulheres de formas coletivas e diferentes em cada esfera.

No outro extremo da teoria, o público versus privado encontra análises em correntes como as do maternalismo político e em uma parte do feminismo negro. Nas primeiras, tais como em Jeahn Elshtain e Carol Gilligan, o privado é entendido como um espaço fundamental para a constituição das mulheres, na qual desenvolvem uma ética específica e um senso de moralidade melhor do que o masculino - a chamada "ética do cuidado" - "o desenvolvimento das mulheres aponta em direção a uma história diferente do vínculo humano" (GILLIGAN, 2013, p. 105). Para autoras como Patricia Hill Collins, entender o privado apenas como um lugar 
de opressão desconsidera as relações de raça e classe que o atravessam. Collins (2000) mostra como a experiência de público e privado para as negras é bastante distinta, porque, ao precisar combater o racismo público, as famílias e os espaços domésticos se tornaram arenas importantes de construção do "eu” e do "nós”. Bell Hooks (1990, p. 423) também sustenta que, por vezes, o privado representa "construção de um lugar seguro onde os negros pudessem se afirmar uns aos outros e, assim, curar muitas das feridas infligidas pela dominação racista", dada a dificuldade de desenvolver amor e respeito por si mesmos em uma cultura branca discriminatória.

A família é talvez a instituição sobre a qual o debate de público versus privado se faz de forma mais firme. O trabalho de Susan Okin (1989), "Justice, gender and family", apresenta, de forma bastante contundente, como os espaços familiares não são justos para as mulheres, muito em função das obrigações que se colocam na esfera privada. Seu debate é, centralmente, com a ideia de família rawlsiana, colocada como uma "primeira escola de desenvolvimento moral" ou "instituição privada", que ignora a construção social que o sexo assumiu quanto as responsabilidades e funções. Ao se referir às teorias da justiça e a seus autores, ela afirma que os "homens, sujeitos das teorias, foram capazes de fazer a transição da vida doméstica para a vida pública com facilidade, em grande parte por causa, das funções desempenhadas pelas mulheres na família" (OKIN, 1989, p. 84). Embora as atividades desempenhadas pelas mulheres sejam fundamentais, continuam marginalizadas no pensamento sobre justiça, como se “acontecessem fora do escopo das teorias" (OKIN, 19895, tradução nossa).

Jean Cohen (2012), por sua vez, desenvolve uma discussão sobre público e privado que nos parece bastante adequada, dado que sua defesa tem implicações para a forma como olhamos a emergência do movimento feminista na mídia. Para Cohen, não é salutar simplesmente abolir a

\footnotetext{
3 Tradução nossa. No original: "construction of a safe place where black people could affirm one another and by so doing heal many of the wounds inflicted by racist domination" (bell hooks, 1990, p. 42).

4 Tradução nossa. No original: "men, the subjects of the theories, were able to make the transition back and forth from domestic to public life with ease, largely because of the functions performed by women in the family" (Okin, 1989, p. 8).

5Tradução nossa. No original: They must be assuming that women, in the gender-structured family, continue to do their unpaid work of nurturing and socializing the young and providing a haven of intimate relations-otherwise there would be no moral subjects for them to theorize about. But these activities apparently take place outside the scope of their theories. Typically, the family itself is not examined in the light of whatever standard of justice the theorist arrives at. (Okin, 1989, p. 8).
} 
distinção entre as duas esferas ou a própria necessidade de existência de um privado. Não basta, segundo a autora, apenas desconstruir os conceitos sem "redescrever o bem que é protegido pela privacidade" (p.169). Longe de um discurso maternalista ou biologizante, Cohen situa no privado as relações pessoais mais necessárias para a constituição dos sujeitos. O problema para ela não é a existência em si da arena privada, mas as relações danosas que se constituem na mesma, garantindo "o direito de não ter as necessidades constitutivas de sua identidade violadas ou submetidas à interferência do Estado", e não transgredindo o que autora chama como as "exigências de justiça” (COHEN, 2012, p.177).

Como uma das autoras feministas que não abandonam o potencial crítico da esfera pública, embora teça suas severas críticas, Cohen atribui a essa revisibilidade permanente de estar e engajar-se no mundo de forma intersubjetiva a capacidade de definição das fronteiras entre os dois espaços. A linha entre as duas esferas é bastante tênue e aberta às revisões e contestações. "É no interior de um discurso público generalizado que se produz em última instância a determinação do que deve ou não deve ficar sob a capa protetora dos direitos de privacidade" (COHEN, 2012, p. 190). Cabe, assim, especialmente ao movimento feminista articulado, reivindicar como já faz - a porosidade entre as duas esferas, sem desmerecer as contribuições que pensar o privado tem para lutas importantes, como o direito ao próprio corpo.

Como este breve resgate tentou demonstrar, a relação entre público versus privado é interpretada de maneiras distintas na teoria feminista, mas trata-se de uma questão importantíssima que ajuda a compreender estratégias do próprio movimento. Não é exagero dizer que quase toda grande obra ou escritora feminista tem algo a sinalizar sobre essa diade conceitual. É a partir da centralidade deste debate que entendemos ser necessário olhar para a sua manifestação nas notícias. Apostamos que essa dimensão analítica construída pela teoria política feminista nos fornece um caminho para como o próprio ativismo foi narrado. Quais quadros sobre público e privado se desenharam na cobertura jornalística sobre o feminismo brasileiro ao longo de quase um século? 


\section{O feminismo nas notícias: definições metodológicas e análise empírica}

A ideia de analisar a presença do feminismo nas notícias se deu a partir da percepção de que, embora haja no cenário nacional vários trabalhos sobre comunicação e gênero focados na representação de mulheres ou em pautas do movimento e ainda detidos na imprensa feminista (SARMENTO, 2013; 2017), observamos uma lacuna no concernente a estudos longitudinais que se dediquem à presença do próprio movimento como um ator político na mídia em diferentes fases.

A partir da ideia de ondas da historiografia feminista (PINTO, 2003) e de campos discursivos de ação feministas (ALVAREZ, 2014), nossa pesquisa se dividiu em três momentos históricos: a) durante a chamada primeira onda e até a emergência da segunda - 1921 a 1959; b) início da segunda onda 1960 a 1989; c) começo da terceira onda -1990 a 2016. Na primeira fase, a historiografia acentua a luta pelo sufrágio, educação e trabalho; na segunda, toda a discussão sobre liberdade e direitos sexuais e reprodutivos; na terceira, uma discussão sobre a entrada do movimento em espaços mais institucionais e novas configurações do ativismo.

A coleta foi realizada a partir da página online "Acervo Folha". A escolha pelo jornal Folha de S. Paulo se deu pelo fato de que, à época da coleta, era o periódico de circulação nacional com o maior número de textos com as palavras-chave da pesquisa. Além disso, mesmo com profundas mudanças politico-editoriais e de distribuição do local para o nacional, era o jornal com acervo disponivel desde a primeira onda do ativismo feminista, dado que foi fundado como Folha da Noite, em 1921. É preciso lembrar que, em julho de 1925, foi criada a "Folha da Manhã" como edição matutina do periódico e, em 1949, a Folha da Tarde, sendo que esta não consta no atual Acervo Online do jornal. Na década de 1960, ocorre a fusão dos três periódicos com o surgimento da Folha de S. Paulo6.

\footnotetext{
6 Tal década marcou ainda o início da modernização do jornal, que se tornaria, nos anos de 1980, o de maior circulação no Brasil e também contaria com a primeira redação informatizada (1983). O site do jornal também informa que a "Folha desempenha um papel decisivo no processo de redemocratização do Brasil, quando abre suas páginas ao debate de ideias que fervilhavam na sociedade civil". Segundo o texto, em 1976, "começa a circular "Tendências/Debates", que abriga textos de intelectuais e políticos perseguidos pelo regime militar". Outra narrativa sobre a história da Folha, extremamente relevante, é realizada pelo Centro de Pesquisa e Documentação de História Contemporânea do Brasil, o CPDOC, da Fundação Getúlio Vargas. De acordo com o documento, à época do golpe militar, "a linha editorial a partir de então tornou-se francamente antijanguista e pró-mobilização para o movimento que culminou com os acontecimentos de 1964". Disponivel em:
} 
Após a pesquisa por uma lista de palavras-chave, com termos como "feminismo", "movimento feminista", "feminista", "sufragista", "movimento de mulheres, "luta das mulheres" (e as variações no plural) construímos uma amostra probabilística a partir de todos os casos encontrados, dado o universo numeroso (à época, mais de 9 mil ocorrências). Realizamos uma amostra estratificada por onda, com erro amostral de 3\% e 97\% de confiança, isto é, cada período apresentou uma quantidade específicas de páginas a serem analisadas. Nossa amostra aleatória estratificada e representativa por onda chegou a 995 casos ou páginas, sendo 123 para o primeiro estrato (12\%), 463 para o segundo (47\%) e 409 para o terceiro (41\%). Construímos, então, três bancos de dados diferentes (um por onda) e, em cada um deles, realizamos um sorteio aleatório, a partir do programa Stata, das matérias que precisavam ser coletadas para cada onda, com base na data de publicação e número de página. O número efetivo de matérias analisadas é descrito em cada onda específica, dado que, no sorteio, apareciam textos ficcionais, horóscopo, resenhas e sinopses de filmes, notas em colunas sociais, dentre outras, surpreendentes, narrativas não analisadas. Ao final, trabalhamos com 579 textos.

Para a operacionalização metodológica, mobilizamos as discussões qualitativas de análise de enquadramento. O uso desta metodologia, a partir da obra de Erving Goffman (1974), tem sido muito frequente na Comunicação e nas Ciências Sociais, ao ponto de um dos seus principais autores, Robert Entman (1993), falar de um paradigma fraturado, em virtude dessas variedades de compreensão do que é um enquadramento e da aplicação de múltiplas técnicas para "encontrá-1o", "descobri-1o".

Quadros, para Stephen Reese (2007, p. 150) são “estruturas que desenham limites, estabelecem categorias, definem ideias". Para Dennis Chong e James Druckman (2007, p.111), os frames referem-se a processos em que pessoas desenvolvem ou revisam conceitos sobre uma questão ao serem expostos a determinados estímulos e não podem "ser confundidos com argumentos moralmente ou intelectualmente superiores", nem como temáticas específicas. Ricardo Mendonça e Paula Simões (2012) afirmam que diferentes

http://www.fgv.br/cpdoc/acervo/dicionarios/verbete-tematico/folha-de-sao-paulo. Acesso em 07.07. 2019. 
produtos midiáticos são objetos mais comuns das análises de enquadramento, embora não se encerrem neles.

Sobretudo ligado à aplicação nos estudos de jornalismo, Elton Antunes (2009, p. 91) pondera que "o frame não se confunde com assuntos de uma notícia, mas, agindo no âmbito de composição do relato, informa vários niveis do processo de referencialização da realidade". Já Carlos Carvalho (2009, p. 4) fala do frame atuando no tornar notícias inteligiveis, ou "relacioná-las a alguma dimensão do social reconhecível por quem as receberá".

Combinamos essas reflexões com a discussão da teoria política feminista, a partir da ideia de master frames critico-feministas. Master frames são quadros de sentido alargados que podem ser mobilizados por diferentes atores (SNOW E BENFORD, 1992). A construção do conceito está ligada à literatura de movimentos sociais, em especial as de teoria do processo político. É uma forma de explicar que, embora os movimentos tenham seus quadros específicos, algumas reivindicações, segundo esses autores, podem ser entendidas como universais, como se atravessassem todas as lutas sociais. Um exemplo clássico dessa literatura são as mobilizações em torno de quadros-mestre de "justiça e injustiça". Movimentos sociais utilizam em seus processos de contestação discursiva pública esses grandes quadros para se opor às narrativas das elites sobre processos políticos em disputa. De acordo com David Snow e Robert Benford (1992, p. 1387),

Os quadros principais são genéricos (...). Assim concebidos, os quadros principais podem ser interpretados como funcionando de uma maneira análoga aos códigos linguísticos, na medida em que fornecem uma gramática que pontua e sintaticamente conecta padrões ou acontecimentos no mundo.

Os autores compreendem os frames como esquemas interpretativos que colaboram para condensar o "mundo lá fora", dando sequência e compreensão aos acontecimentos presentes ou passados (SNOW e BENFORD, 1992, p. 137). Master frames, por sua vez, funcionam em maior escala, como se colaborassem para inteligibilidade mais generalizada das demandas disponíveis em lutas públicas.

\footnotetext{
7 Tradução nossa: No original: Master frames are generic (...)So conceived, master frames can be construed as functioning in a manner analogous to linguistic codes in that they provide a grammar that punctuates and syntactically connects patterns or happenings in the world.
} 
Embora a ideia de uma gramática comum que englobe reivindicações de movimentos sociais seja bastante interessante, não é possível deixar de pontuar que os termos em que a própria teoria dos movimentos sociais e as ideias tidas como esses quadros-macro também estão inscritas em um processo hierárquico de vivência de mulheres e homens. É a partir de toda a discussão que trouxemos da política contestada pelas ideias feministas da crítica à divisão liberal organizadora das relações de público e privado, bem como da entrada de novos assuntos como problemas pesquisáveis nesse seio disciplinar, que entendemos que é possivel pensar em master frames de crítica feminista para analisar os meios de comunicação e a relação das feministas com eles.

Entendemos que a relação entre público versus privado é um frame feminista que pode auxiliar na compreensão sobre o aparecimento público do movimento via jornal. A partir dessa ideia, após a coleta de todas as páginas sorteadas na amostra, construímos um banco de dados para cada onda, com data, título, presença de fontes, temas principais de cada texto. Em seguida, identificamos se a notícia, reportagem ou artigo abrigava compreensões sobre público e privado. Nos textos em que era possível observar a relação entre as esferas, anotávamos como essas relações se davam, quais os termos utilizados e os argumentos sobre ocupação de espaços e vivência de comportamentos ligados aos dois âmbitos. A ideia de mapear essa relação se mostrou bastante dificil empiricamente, primeiro porque não trabalhamos com uma temática específica por onda, mas com as matérias sobre o ativismo em si. Essa busca está inspirada na proposta de Van Gorp (2007), dado que temos a) um fenômeno cultural a ser analisado (a atuação do movimento feminista ao longo do tempo); b) raciocínios latentes (em que se constroem visões sobre esse ativismo); c) dispositivos de enquadramento (visiveis em termos qualificadores positivos ou negativos tanto do sujeito - sufragistas, feministas acadêmicas, 'feminazis' -; como das relações entre público e privado - política/cuidado com os filhos, trabalho/casa etc).

Após a finalização da leitura do conjunto de notícias por onda, voltávamos às anotações sobre público versus privado percebendo como as notícias se aproximavam ou não, quais ângulos se mostravam ressaltados 
nessa cobertura. Indicamos com um mesmo número as que apresentavam compreensões semelhantes e depois construimos um novo banco juntando essas aproximadas. Ao final, relemos todas aquelas que nos indicavam ter compreensões similares sobre e público e privado e adicionamos um "rótulo" que conseguisse descrever os enquadramentos encontrados.

Passaremos a seguir à análise dos enquadramentos de público versus privado nas notícias sobre o movimento feminista brasileiro nos três momentos definidos.

\section{O insulamento e a concessão: análise da primeira onda (192 I a 1959)}

Nesta primeira fase, foram coletadas 123 páginas dos periódicos, divididos ainda entre Folha da Manhã e Folha da Noite. Foram excluídos textos ficcionais, notas em colunas sociais e os que estavam ilegiveis pelas condições de digitalização, com 103 textos efetivamente analisados, sendo $41,58 \%$ de notícias nacionais, 34,65\% de textos internacionais, $21,78 \%$ de artigos de opinião e o restante, com pouca expressividade, de reportagens e perfis.

Nesse primeiro período, que corresponde ao Brasil da Primeira República vivendo um processo crescente de urbanização e marcado na historiografia feminista sobretudo pela campanha sufragista, com o estabelecimento do voto feminino na Constituição em 1934, a relação entre público e privado aparece como fundada na oposição entre as duas esferas. Dois frames se mostram fortes na construção dessa distinção, especialmente ligados à preponderância de textos sobre sufrágio feminino: o enquadramento do insulamento e o enquadramento da permeabilidade via concessão.

O primeiro frame é aquele em que os domínios de público e privado aparecem como opostos e assim deveriam se manter, insulando as mulheres no privado e os homens no público. O terreno da política institucional ou dos cargos de confiança são os exemplos, nas notícias, do domínio público. Ressaltamos que o sufrágio feminino foi um dos temas mais recorrentes nas notícias.

Mais do que uma dimensão espacial, em tal enquadramento, apontase para as habilidades especificas de homens e mulheres. Haveria diferentes 
"aptidões" que sinalizam a separação das esferas, com claro prejuízo às mulheres, como alerta Pateman (1993). Neste sentido, um dos argumentos que trata dessa distinção, presente nos textos do corpus, sustenta a importância de proteger as mulheres dos processos que compõem o jogo político, eminentemente masculino. Percebe-se, aqui, um modo de afastar as mulheres deste cenário, focando na aridez ou na perversidade da política formal:

Pretende-se dar direito de voto às mulheres, aproveitando a brecha da reforma constitucional. O "leader" mineiro do Senado é contrário á iniciativa. Como de tudo se faz troça, nos corredores das câmaras, o caso da emenda feminista tem sido assumpto preferido, em torno do qual se fazem commentarios de todo o genero (...) - Aqui está, a meu ver, o perigo maximo da concessão de direito de voto ás mulheres: meia duzia de senhoras bonitas assim tomavam conta da Republica em três tempos. O sr. Barbosa Lima se reveste de coragem e resolveu pedir a opinião do austero e secco senador pelo Amazonas. - O que pensa, V. exa?. - Nem se discute. Nega (...). $\mathbf{E}$ caridade conserval-as alheias dos processos empregados para que seus maridos sejam representantes do povo (Indiscreções no Rio, Folha da Noite, 05/09/1925, Caderno Único, p.1, grifos nossos).

Um exemplo evidente dessa oposição é visualizado na notícia referente à não contagem dos votos de mulheres do Rio Grande do Norte para eleição ao Senado. De acordo com o excerto, o direito ao voto só foi atribuído a elas dentro do estado e, por isso, fez-se bem em descartar seus votos nacionais. Sobre a luta delas para exercer o direito político, diz-se que está se "forçando uma entrada":

[...] Riscando os votos das onze eleitoras nortistas, muito bem terá andando a Camara alta da Republica. Não se desconhece o direito que o Rio Grande do Norte deliberou atribuir a suas filhas. O que se contesta é o direito dellas sendo eleitoras apenas dentro das fronteiras do Estado, isto é, podendo intervir nas eleições estaduaes e municipaes, quererem, logo de começo, dilatar esse direito até ás eleições federaes. Se é assim que pretendem trazer o seu contingente para a moralização de nossos costumes, iniciando a sua actuação no scenario politico do paiz por um caminho tortuoso, forçando uma entrada que, por emquanto, lhes está vedada, será melhor que as damas jamais pensem em trocar o seu imperio no lar, pela vassallagem nos dominios da politica (Sem título, Folha da Manhã, 20/05/1928, p. 5, grifos nossos).

O "império do lar" e os "domínios da politica" aparecem, conforme trecho supracitado, em extremos da vida social, separados espacialmente, mas também, e sobretudo, pelo gênero das pessoas que os ocupam. Aparecem opostos nos textos, mas na perspectiva de Okin (1989) essa 
distinção não existe, dado que o condicionamento do sujeito feminino ao privado é o que permite a agência dos homens no público, como as mesmas matérias deixam ver.

Um segundo frame presente nas notícias do período é o que denominamos de enquadramento da permeabilidade via concessão, especialmente ligado à entrada das mulheres no que é entendido como público. Para adentrarem em arenas como a politica e a esfera do trabalho ou mesmo para promoverem mudanças de atitudes, as mulheres precisavam passar pelo crivo daqueles já autorizados a atuar no público, os homens.

Nos textos dos periódicos, os homens que viram nas mulheres um filão eleitoral, dizem os jornais, "vão aparecer, agora, às centenas".8 Há também insinuações de que os representantes do legislativo e Executivo engajados na discussão sobre o sufrágio estavam mesmo interessados nas mulheres - "Mas o sr. Lamartine, ao lado dessa feição política, adepto do feminismo, anda agora bancando o "pé de Alferes" (...) enveredando pelo donjuanismo (...)"9.

Pouco inteligivel, se comparado ao Português atual, e recheado de ironias, o texto opinativo abaixo traduz a ideia que circulava de que os direitos ali requeridos, "esse negocinho de mecês votarem", não vingariam sem a aprovação dos homens.

[...] Têm paciencia, bemzinhos, não póde ser assim. Por oramente é "diffécil" admittir nas urnas o fructo prohibido da emancipação cotó do cabello sura, com liberdades de meia cor de carne e outros perigos amarellos á beira mar plantados. "Tenheis" paciencia, ilustres "cidadôas", mais tarde, talvez, quem sabe seja possivel arranjar-se esse negocinho de mecês votarem. No momento, porém, não cabe a pretenção (...) Esperem um pouco, senhoras sufragistas, nãos e deve ir com tanto póte á sede, porque devagar se vae ao longe e de mansinho chega-se lá... (Sem título, Folha da Noite, 26/05/1928, Caderno Único, p. 1).

Público e privado só aparecem de forma intercambiada a partir da anuência masculina. Se há uma forma mais legítima de militar pelos direitos das mulheres, ela também está acompanhada, na narrativa jornalística, das brechas permitidas pelos homens. Tomando emprestada a ideia de que a opressão tem várias faces, de Young (1990), podemos notar no contexto de disputa discursiva sobre o voto feminino um exemplo de marginalização, cujos contornos são construídos pela dominação masculina. Marginalizados,

\footnotetext{
8 Sem título, Folha da Manhã, 13/11/1927, p. 8.

9 O feminismo do Sr.Lamartine, Folha da Manhã, 11/01/1929, p. 5.
} 
para Iris Young (1990, p. 53), são pessoas expulsas da participação na vida social, ou que são atravessadas por processos de "privação de condições culturais, práticas e institucionalizadas para o exercício de capacidades em um contexto de reconhecimento e interação" (YOUNG, p. 1990, p. 55).

O discurso público que circulava via notícias já se mostrava atravessado ali pelas perturbações do feminismo de primeira onda. Os próximos anos iriam acentuar a presença do movimento no jornal.

\section{A intersecção: análise da segunda onda (1960 a 1989)}

Os deslocamentos provocados pelos novos sujeitos do feminismo na segunda onda tiveram implicações no modo como as relações de público e privado foram enquadradas, neste período que é marcado pela longa ditadura militar vivenciada no país e pela abertura democrática, já na segunda metade dos anos 80. Foram coletados para esse periodo de análise 485 textos e 274 foram analisados. Os textos não centralmente enfocados na análise estão relacionados, especialmente, com a cultura popular. Foi bastante impressionante o número de sinopses de filmes, livros e peças de teatro, textos de crítica literária ou textos ficcionais que mobilizavam personagens feministas. Dos 274 textos analisados, em torno de $36 \%$ eram de material opinativo, seguidos de $27,37 \%$ de notícias nacionais, $19,71 \%$ de notícias internacionais e um crescimento dos gêneros de reportagem $(5,47 \%)$ e entrevista $(4,74 \%)$.

A partir dos anos de 1960, as pautas trazidas pelo movimento, sua organização e seus ganhos interpelaram o enquadramento dessa relação. As arenas continuam a ser apresentadas como distintas nas notícias e textos opinativos, mas o frame dessa relação se altera. Neste sentido, identificamos nos textos o que chamamos de o enquadramento da intersecção.

Um tema da cobertura jornalistica sobre o movimento feminista em que a intersecção entre público e privado se torna evidente é o relativo às relações de trabalho e às implicações para o cuidado da vida doméstica e das crianças, que emergem nos textos.

Como o emprego da mão-de-obra feminina, em trabalhos formais e informais, tornava-se crescente, atividades relegadas às mulheres (como cuidado, por exemplo) passavam a ser problematizadas. A feminista 
Heloneida Studart, ouvida em entrevista pelo Folhetim, afirmava que as questões trabalhistas em voga à época deveriam ser lidas sob o viés do gênero. Os desafios da conciliação entre trabalho e maternidade passavam pelo domínio público e não estavam apenas restritas a resoluções privadas ou individuais:

\begin{abstract}
"Nós não podemos dizer que a causa da mulher é apenas a causa dos trabalhadores, ela também tem uma especialidade. Como trabalhadora a mulher também é mal assalariada, é mal apoiada, a legislação não a favorece (...). Sem contar que a mulher não é apoiada em seu trabalho, nem por creches, por nenhum tipo de equipamento coletivo. Isso é um absurdo, porque é como se as pessoas pensassem que o filho pertence à mulher. O filho pertence à sociedade. A mulher não deve e nem precisa cuidar do filho sozinha. Ela não vai botar o filho na prateleira. O filho é um ser social. Então, a sociedade é tão responsável quanto a mãe pela criação desse filho" (Mulher de verdade, FSP, 13.08.1978, Folhetim, p. 2-4).
\end{abstract}

As implicações psicológicas e das pressões sociais foram trazidas à tona. Agora, dizem alguns textos, elas precisavam lidar com uma "dicotomia": "ou você é boa mãe ou você é profissional":

\begin{abstract}
Nós, mulheres, dificilmente escapamos da culpa de sermos bemsucedidas fora do lar. Por criar, por trabalhar. (...) Penso que nós, mulheres, somos ensinadas a acreditar que existe uma dicotomia incontrolável: ou você é boa mãe ou você é profissional. Dificilmente temos exemplo dos dois ocorrendo em harmonia. E aí sentimos sempre que temos que escolher. O que provoca muita angústia. (...) $\mathrm{O}$ crescimento da mulher não apaga, necessariamente, o do homem nem "priva" os filhos. Pode estimular o homem e a família a crescer("Leis", "normas", e "obrigações" que só valem para mulher, por Marta Suplicy, 29.05.1983, FSP, Mulher, p. 5).
\end{abstract}

A relação de intersecção entre público e privado também se manifesta quando questões historicamente identificadas como exclusivamente femininas passam a ser tratadas no público. Ou mesmo quando uma arena, tal como a política formal, construída sob o privilégio masculino, vê-se interpelada pelas mulheres. O lugar de fala delas pautando questões da vida pública e politizando o que era tido como pessoal fica claro nos movimentos pró-diretas $^{10}$ e em notícias internacionais sobre participação política eleitoral ${ }^{11}$. Agora não era só o direito de votar e ser votada, como as sufragistas; mas também de levar ao âmbito da construção politica o que era tido como da esfera da casa. Até os candidatos dos pleitos sub-nacionais que se organizavam no período da redemocratização foram questionados, em

10 Romper tutelas, Marilena Chauí, 20.02.1984, FSP, Opinião, p.2.

11 As feministas aproveitam o ano eleitoral, 11.03.1978, Exterior, p.11. 
debates, sobre "temas impertinentes", tais como aborto e homossexualidade ${ }^{12}$.

No próximo dia 24, o Movimento de Mulheres Pró-Diretas promoverá passeata em favor do pleito para a presidência da República (...) Além das eleições, há outros assuntos a serem levantados: creches, modificações no Código Civil, protesto contra o controle da natalidade "imposto pelo FMI" - de acordo com o folheto de convocação - e a violência contra a mulher. (...) $E$, às que quiserem ajudar na promoção da passeata, as organizadoras sugerem que façam como as integrantes dos movimentos femininos de Minas: ligar para mais cinco mulheres e convidá-las a participar (Mulheres farão passeata em SP dia 24, 15/02/1984, FSP, Política, p. 4).

Especialmente a partir das comemorações da década da mulher ${ }^{13}$, vários temas ligados à vida privada passaram a ser pautas questionadoras da oposição entre as esferas: aborto ${ }^{14}$, contracepção e planejamento familiar ${ }^{15}$ e violência eram temas que borravam essas fronteiras, embora a cobertura não seja necessariamente positiva. Em 1977, uma matéria questionava as leis de repressão à violência contra as mulheres e ouvia fontes que falavam sobre "a cristalização da cultura na ótica masculina, já que são eles, os homens, os responsáveis pela formulação das leis e das decisões judiciais"16. O título do texto, contudo, não refletia a luta do período. Estampado no jornal, lia-se: "Cuidado, nem todas gostam de apanhar".

Três mulheres foram ouvidas pela Folha para o balanço de conquistas e desafios dos anos 70: "a psicanalista Maria Rita Kehl, a antropóloga Ruth Cardoso e a socióloga Carmem Barroso". A década de 80 terminava, segundo elas, mesmo com os problemas, com a absorção do feminismo pela sociedade:

Ruth: A questão do feminismo não é se a discriminação está na sociedade ou está na casa, é da discriminação onde ela ocorra. E ela ocorre no mercado de trabalho, pelo fato de ser mulher e na casa, também pelo fato de ser mulher.

Carmem: Essa foi a mudança importante dos últimos dez anos. Hoje, é praticamente consenso que as coisas estão ligadas. A ligação entre o espaço doméstico e o espaço não doméstico, é a ligação entre o

\footnotetext{
12 Os candidatos e os temas impertinentes, 04/08/1982, FSP, Tendências e Debates, p. 2

13 Amanhã, Dia Internacional abre a primeira década da mulher, criada pelo AIM, 07.03.1976, FSP, Nova Mulher, p. 53 /Ano Internacional agenda para o futuro o início da década da mulher, 19.06.1975, FSP, Nova Mulher, p.37

14 Para juristas, as leis contra o aborto são "repressivas", Silvia Helena, 21.12.1989, Local, p.19/ O aborto em questão, 26.04.1981, FSP, Folhetim, p. 6-7.

15 Pilula anticoncepcional ainda gera polêmica, 10.03.1985, Geral, p. 26.

16 Cuidado, nem todas gostam de apanhar, 10/08/1977, FSP, Ilustrada, p. 31.
} 
afetivo e o econômico, é a ligação entre o político e o social (Crise das utopias atinge o feminismo, avaliam cientistas sociais, 18/05/1988, FSP, Política, p. 6).

A oposição entre as duas esferas que marcou as notícias da primeira onda começa a se desfazer. Há um acompanhamento pelo jornal das reivindicações dos grupos feministas que se organizavam e pluralizavam o ativismo nesses anos. Passemos a seguir para o último período temporal da análise.

\section{Entre desnaturalização e re-naturalização: análise da terceira onda (1990-20 I6)}

O enquadramento da relação entre público e privado na terceira onda se dá de forma próxima ao que encontramos na segunda, contudo mais do que apresentadas com pontos de interseção, as esferas são paulatinamente desnaturalizadas. Cada vez mais imbricados, os comportamentos historicamente associados às duas esferas se misturam de forma acentuada na cobertura jornalística sobre movimento feminista. A relação entre público e privado aparece mais difusa e tensionada de diversas formas, sem que a distinção entre as arenas se desfaça. Todavia, é perceptivel, com os ganhos oriundos das lutas mulheres, um processo de re-naturalizar certas conquistas ou comportamentos.

Sobre o corpus, novamente, número de textos efetivamente analisados (202) foi diferente daquele proposto na amostra (409 páginas que se desdobraram em 363 textos ${ }^{17}$ ), dada a presença acentuada dos textos ficcionais, sinopses e demais gêneros já mencionados. Foram 34, 65\% de notícias, 28, 22\% de artigos de opinião e 14,36\% de reportagens. No início dos anos 2000, além de livros e filmes, com o crescimento do acesso à internet, os sites também eram "resenhados" e as primeiras iniciativas feministas online apareceram no jornal. Para fins analiticos, chamamos os quadros de a) o enquadramento da desnaturalização e o b) o enquadramento da re-naturalização.

Uma dimensão em que a desnaturalização das relações público versus privado se mostra acentuada é no uso reflexivo da linguagem. Isso se torna perceptivel a partir das reconfigurações de palavras e expressões pelo

$17 \mathrm{O}$ número menor de textos do que de páginas se explica pelo fato de que um caso poderia ocupar várias páginas, tais como entrevistas ou reportagens dominicais. 
ativismo. A Marcha das Vadias, por exemplo, passava a politizar um termo que era historicamente tido como pejorativo. A vadia é agora pública, reclama respeito, politizando um adjetivo ligado para deslegitimar as mulheres.

A publicitária Madô Lopez, 30, também aposta na "roupa de vento" como forma de chamar atenção para uma causa. A sua é a vadiagem: a grafiteira curitibana é a responsável por organizar a primeira Marcha das Vadias, em 2008, na qual mulheres usam trajes mínimos (ou nenhum) para protestar contra o machismo (Guerra dos pelados, 21/07/2013, Revista são Paulo, p. 26 a 32).

Outro acontecimento que provocou questionamentos do uso da linguagem nesses anos foi sobre o uso flexionado do substantivo de designação do/a chefe do Executivo, com Dilma Rousseff sendo chamada de "Presidenta". Um caso emblemático da ocupação de um espaço, de um cargo e de uma arena ligado à vida pública, então masculina. A linguagem foi assim fundamental na busca por desnaturalizar a ideia de que só existe homem presidente:

É incrivel a dificuldade que certas pessoas têm para perceber o sistema de dominação embutido na linguagem. As regras gramaticais não brotaram do nada, elas têm um histórico secular que pretendeu tornar a mulher irrelevante, a ponto de deixá-la invisivel (...). Mas o mundo mudou, e a linguagem precisa acompanhar essa mudança. É nesse particular que Dilma incomoda os conservadores: ela torna evidente que seu cargo é ocupado por uma mulher. $(\mathrm{O}$ gênero que muda a linguagem, 08/02/2012, FSP, Primeiro Caderno, p. 2).

As notícias também davam conta que comportamentos que insistiam na repetição de estereótipos por meio de expressões e piadas também eram questionados, especialmente por meninas jovens. A ideia bastante difundida de que essas expressões jocosas eram "só brincadeiras", de foro privado, foi pouco a pouco sendo combatida e ganhando visibilidade. Elas eram questões politicas, publicamente discutiveis e começavam a ser tratadas assim:

O movimento feminista mais importante na história é o movimento dos quadris". "Mulher é como filme: só se revela no escuro". Piadas típicas de cursinho pré-vestibular como essas correm risco de extinção. As direções de instituições preparatórias frequentadas pela classe média alta paulistana têm orientado os professores a suspender comentários jocosos no intuito de evitar ameaças judiciais. Alunos e especialmente alunas têm reclamado do que consideram machismo, homofobia e racismo aos pais, que cobram explicações (...) Eu e três meninas saímos da sala quando o professor falou que, se quiser 'comer' a empregada, o cara tem que levá-la ao Habibs, conta Julia Castro, 18, aluna do Anglo de Higienópolis. "Essas brincadeiras reforçam o preconceito. Nossa luta já é dificil 
(Reação de alunos faz professores pararem com piadas de cursinho, 10/08/2014, FSP, Cotidiano, p. 8).

Você sabe o que é sexismo? Vou explicar: quando se afirma que mulher que transa com muitos homens é vagabunda e que um homem que transa com muitas mulheres é bem-sucedido, isso é sexismo. Quando se diz que boneca é coisa de menina e futebol é para meninos, isso é sexismo. Entenderam? Sexismo, como define o dicionário, é uma "atitude discriminatória em relação ao sexo oposto (Coluna GLS, 02/11/2003, FSP, Mais!, p. 5).

Esse quadro da desnaturalização de público e privado se mostra intimamente ligado à discussão sobre a presença das mulheres na politica formal, em cargos eletivos ou não. Como na segunda onda, questiona-se a quantidade pouco expressiva de mulheres, mas passa-se a brigar também pela qualidade da atuação de quem ocupa esses cargos. O questionamento das desigualdades que afastam as mulheres de uma parte do mundo político e as aproximam de outra, especialmente ligadas às questões de cuidado, também se acentuou:

A presença feminina no primeiro escalão das capitais brasileiras é, além de minguada, concentrada nas áreas sociais. Um levantamento feito pela Secretaria Especial de Politicas para as Mulheres (SEPM) nos recém-nomeados secretariados de 26 capitais mostra que 59,9\% das mulheres titulares atuam em áreas como educação e assistência social. Para a secretaria, essas pastas são relacionadas ao cuidado e à extensão da casa e da conduta doméstica. Nas secretarias ligadas a temas econômicos e de gestão contam com 25,3\% das mulheres titulares. A consultora do ONG Cfemea (Centro Feminista de Estudos e Assessoria) Eneida Dutra diz que ainda não foi desconstruído o mito de que as mulheres são naturalmente adequadas para o espaço privado -a casa e a família. A Cfemea realiza estudos sobre o direito das mulheres. "Não podemos tratar isso como uma coincidência, como se as mulheres não se interessassem por outras áreas. Ainda há barreiras de desconfiança em relação à capacidade das mulheres de liderar e de lidar com situações de pressão", avalia (Mulheres são maioria nas pastas sociais, 05/12/2007, FSP, Primeiro Caderno, p. 3).

Em especial com a criação da Secretaria de Politicas para as Mulheres (2003), pautas antes restritas ao foro privado passaram a se institucionalizar, tal como o combate à violência doméstica e a Lei Maria da Penha - "feita por um consórcio de entidades feministas"18. A violência talvez seja a pauta em que essa desnaturalização se acentuou, com a melhoria significativa da cobertura ao passar dos anos. Tentativas de debate sobre o aborto pelas ministras, feministas de longa data, que entravam para o

\footnotetext{
18 Uma lei que pegou?, 22/09/2007, FSP, Primeiro Caderno, p. 2.
} 
Estado também mostravam que público e privado, a partir dos anos 90, estavam cada vez menos dissociados. "Há discussões e temas que são polêmicos na sociedade. A solução para eles não é escondê-los debaixo do tapete. É enfrentá-las, declarou Nilcéa"19, a primeira-ministra de mulheres brasileira.

As reconfigurações da figura masculina nas questões da vida doméstica e da paternidade também integram o enquadramento da desnaturalização. O jornal falava de um "homem em crise", que se viu "perdido" com as conquistas femininas e começava a pensar em movimentos de valorização da masculinidade. De acordo com as notícias, a esfera "deles" estava tomada por elas e eles não sabiam como se comportar tendo que lidar, diz a metáfora do jornal, "com um pano de pratos nas mãos":

O homem em crise seria o que se dá conta do descompasso: como se, enquanto a mulher cuidava de se emancipar, atarefada entre a casa e o trabalho, a maquiagem e o orgasmo, o homem tivesse ficado parado no meio da cozinha, sem saber o que fazer, com um pano de pratos nas mãos até solidárias (...)"Viadagem", declara L., 33, solteiro, horrorizado com a possibilidade de que haja um movimento auto-intitulado "masculinista": "Me desculpe, mas homem não precisa disso. A gente e continua dominando o mundo (...). Mas aqui ela parece ser vista com enorme desconfiança, como se a mera possibilidade da existência da crise já significasse uma ameaça à masculinidade, à virilidade. Todos os entrevistados proibiram a publicação de seus nomes. (Homens em crise, 05/03/1995, FSP, Mais!, p. 4).

Se os avanços da vida das mulheres, muitos deles em função da luta feminista, causavam descompasso no comportamento masculino, o jornal trazia também que o feminismo colaborou para incentivar reflexões sobre uma paternidade mais ativa:

O pai pós-moderno é um filhote do feminismo dos anos 60", diz a terapeuta familiar Isabel Cristina Gomes, professora do Instituto de Psicologia da USP. A psicóloga explica que os maridos das primeiras feministas não dividiam as tarefas de casa: elas podiam trabalhar, desde que não deixassem de lado o cuidado com o lar e os filhos. A maioria dos pais de então davam às crianças uma educação mais liberal do que a que tinha recebido, mas não colocavam a "mão na massa" - trocar fralda, dar papinha, colocar para dormir. Coube às suas mulheres criarem meninos dispostos a reivindicar um papel decisivo na vida dos filhos. (...) O reflexo da participação mais efetiva dos pais de hoje já chegou à esfera jurídica. O novo Código Civil, que entrou em vigor em janeiro, retira da mãe a prioridade na guarda dos

\footnotetext{
19 Ministras querem discutir tema, 10/12/2004, FSP, Cotidiano, p. 4. / STF libera aborto de fetos anencéfalos. 13/04/2012, FSP, Cotidiano, p.1.
} 
filhos menores em caso de separação. (Pai até de madrugada, 10/08/2003, FSP, Revista da Folha, p. 10-15).

Essa fase analisada também abriga textos em que é visivel um processo de re-naturalização de atividades associadas a público e privado. Não se trata de um insulamento, como na primeira onda, mas, diante da intersecção que já marca a relação entre as esferas, observamos uma retomada de opiniões que buscam novamente associar especialmente às mulheres às atividades exclusivas do privado.

Um exemplo claro, fartamente documentado, é o questionamento acerca da vida pessoal das mulheres que alcançavam os altos postos politicos. A literatura sobre a cobertura de mulheres politicas atesta que essa é uma infeliz marca da visibilidade midiática dessas agentes (NORRIS, 1997; ROSS, 2002). O marido e a família são sempre questões para as representantes femininas, incluindo as declaradamente feministas:

Folha: A sra. sonhava em ser senadora?

Eva Blay: Claro. E lutei muito para conseguir. Como suplente de Fernando Henrique Cardoso, participei ativamente da campanha. Sou a primeira senadora paulista eleita com voto popular - Dulce Salles Cunha Braga, a primeira mulher a ocupar o cargo, 1982, foi indicada pelo governo federal.

Folha: Normalmente é a mulher quem acompanha o homem. No seu caso, a inversão vem de sua prática feminista?

Eva Blay: De nossa prática feminista. Temos uma prioridade: ficarmos juntos. Se aparecesse uma oportunidade fascinante para ele, eu o seguiria. Acho normal que ele me acompanhe.

Folha: Seu marido é o marido dos sonhos de uma feminista?

Eva Blay: É

Folha: Por quê?

Porque ele também é feminista. (A senadora que planeja a vida, FSP, 13/12/1992, Revista da Folha, p. 20).

A maternidade voltava à cena para ajudar a justificar essa própria entrada na politica. Esse é um exemplo da re-naturalização dessa relação. Por vezes, recorre-se a ideias naturalizadas sobre uma esfera para justificar a necessidade da outra:

A mãe do PAC (Programa de Aceleração do Crescimento) e candidata do presidente Luiz Inácio Lula da Silva à sua sucessão, Dilma Rousseff, teve uma boa oportunidade para defender a participação das mulheres em cargos públicos, incluindo a Presidência, ontem em São Paulo. Aconteceu depois que a ministra da Casa Civil tomou café da manhã com a primeira mulher presidente do Chile, Michelle Bachelet. $O$ encontro serviu, contou Bachelet, para que ela convidasse a ministra para um evento no Chile em setembro, justamente para falar do PAC. Mas, como o temário incluiu a "troca de experiências" sobre como é ser mulher no comando no ainda masculino e sexista mundo político, foi a chance para Dilma elogiar o 
modelo pós-feminista de Bachelet (por essa corrente entenda-se a que não rejeita como preconceito o elogio de algumas características consideradas femininas, incluindo os atributos da maternidade). (...) "Hoje em dia o Brasil pode ter tudo, já teve um presidente metalúrgico, pode ter um presidente negro, pode ter uma presidenta. A sociedade brasileira é madura o suficiente para saber que a sua multiplicidade pode ser representada de todas as formas", disse Dilma, que repetiu o "nem amarrada" quando instada a falar sobre 2010. Dilma lembrou a trajetória da colega, sem citar as semelhanças. Mas tanto a ministra como Bachelet foram presas e torturadas durante as respectivas ditaduras. Bachelet foi para o exílio, mas não escapou na campanha de acusações de que havia atuado no planejamento de atentados nos anos 80. Ambas passaram por áreas não tão comuns para mulheres na região: a brasileira, em energia, a chilena, na Defesa. As duas são solteiras. Nenhuma delas rejeita a projeção do papel de "mãe". O termo foi usado pelo sociólogo chileno Patrício Navia em entrevista à Folha para dizer que Bachelet preferia ser "mãe" dos chilenos a lutar para valer no jogo político. Bachelet defendeu seu estilo "dialogante". A mãe do PAC, questionada, ampliou o argumento: "Uma presidente que é mãe dos chilenos cumpre as duas obrigações de um governante: cuidar de seu povo e dirigir sua casa, seu país. Ser mãe é um fator positivo" (Dilma encontra Bachelet e diz que Brasil já é maduro para ter "uma presidenta", 31/07/2009, FSP, Primeiro Caderno, p.10).

Como nas demais ondas, os discursos de oposição ao feminismo também ganhavam espaço. Na re-naturalização da relação entre público e privado, em um texto intitulado "Desgraça do feminismo", um articulista do jornal afirmava que as crianças estavam sendo prejudicadas com a saída das mulheres para os empregos fora de casa. Era preciso, segundo ele, combater esse "exagero" e acabar com o "tabu" de que as mulheres precisavam trabalhar fora.

Como quase todos os movimentos sociais, no entanto, o feminismo criou novas injustiças, produtos de exageros ou distorções de seus principios. Uma delas transforma em suas vítimas as crianças. (...) O que não faz sentido é se criar um contingente de crianças inseguras, frustradas e incompetentes apenas para se satisfazer às exigências de um tabu social de que a mulher só é mulher na sua plenitude se tiver emprego fora de casa. É preciso acabar com essa desgraça do feminismo (Desgraça do feminismo, 20/10/1992, FSP, Opinião, p. 2).

Esses dois quadros apontam para um processo complexo que tem na imprensa tanto uma aliada importante na desnaturalização de concepções históricas sobre questões que atravessam público e privado, como, ao mesmo tempo, um crescente tratamento re-privatizante das mulheres.

\section{Considerações finais}

Após a análise, baseada em uma amostra, de 95 anos de cobertura sobre o ativismo feminista no jornal Folha de S. Paulo, é possivel admitir que 
há uma passagem clara, no discurso midiático, de argumentos que sustentam o afastamento das mulheres do público e inscrição nelas do privado, para aqueles que passam a tensionar essa divisão. $O$ que depreendemos desses textos é que houve, ao longo do tempo, um aprendizado oriundo das mudanças na sociedade brasileira, o qual advém fundamentalmente da forma como as ativistas feministas interpelaram as dinâmicas de opressão, desigualdade e hierarquia. Contudo, é possivel notar também um processo de re-naturalização das discussões sobre público e privado, que se aproxima das ideias de maternalismo e à ética do cuidado (GILLIGAN, 2013).

Essa pesquisa também corrobora os achados de Kaitlynn Mendes (2011a; 2011b; 2012), que mostra uma prevalência de discursos mais positivos sobre o movimento feminista na contemporaneidade do que encontraram pesquisadoras de décadas anteriores e, sobretudo, do que dizem às próprias mulheres sobre sua presença midiática enquanto militantes.

Contudo, a autora também afirma que, mesmo com essas insercções positivas, "discursos de retrocesso (backlash) tendem a emergir em tempos de renovado feminismo" (MENDES, 2015, p. 227, tradução nossa), tais como nas recentes marcações das feministas como "feminazi". Essa dinâmica de visibilidade positiva e negativa aparece nos três periodos analisados, de forma que não é possivel afirmar a presença isolada de um ou outro discurso. Notícias ou textos opinativos claramente antifeministas apareceram no mesmo jornal que realizou coberturas densas sobre o movimento.

É interessante retomar a ponderação de Cohen (2012), apresentada na primeira parte do paper, sobre como a luta feminista é fundamental para que o que concerne às esferas de público e privado seja produzido de forma dinâmica e também discursivamente. A autora tem apostado que o tratamento público das questões que afetam as vidas mulheres é fundamental para que o privado não se confunda com opressão. Com a análise dos jornais, é possivel perceber como a politização das diferentes questões pelo movimento feminista vai ganhando força e espaço na cobertura. 
Todavia, é necessário retomar também as ideias de Walby (1990), sobre os transbordamentos do patriarcado. Mesmo que em alguns momentos haja uma consideração mais positiva sobre as pautas ou sujeitos do feminismo, conseguimos perceber falas bastante agressivas sobre o movimento e suas demandas. É o que autora entende como um fluxo não linear de combate à desigualdade de gênero; espaços ou pautas podem se tornar mais socialmente compreensiveis ou aceitos, enquanto outros ainda são extremamente marcados e entendidos a partir da hierarquia desfavorável às mulheres.

\section{Referências}

ALVAREZ, Sonia. Para além da sociedade civil: reflexões sobre o campo feminista. Cadernos Pagu, Campinas, n. 43, 2014, p. 13-56.

ANTUNES, Elton. Enquadramento: considerações em torno de perspectivas temporais para a notícia. Revista Galáxia, São Paulo, n. 18, 2009, p.85-99.

BARKER-PLUMMER, Bernadette. News and feminism: a historic dialog. Journalism \& Communication Monographs, 12, 2010, p. 145-203

CARVALHO, Carlos Alberto. Sobre limites e possibilidades do conceito de enquadramento jornalístico. Contemporânea, Salvador, vol. 7, n 2, 2009, p. $1-15$.

CHONG, Dennis; DRUCKMAN, James N. Framing theory. Annu. Rev. Polit. Sci., 10, 2007, p. 103-26.

COHEN, Jean. Repensando a privacidade: autonomia, identidade e a controvérsia sobre o aborto. RBCP, Brasília, n. 7, 2012, p. 165-203.

COLLINS, Patricia Hill. The Social Construction of Black Feminist Thought. In: _ Black Feminist Thought: Knowledge, Consciousness, and the Politics of Empowerment. NY: Routledge, 2000, p. 1-44

ENTMAN, Robert. Framing: towards clarification of a fractured paradigm. Journal of Communication, v. 43, n. 4, 1993. p. 51-58,

GILLIGAN, Carol. Imagens de relação. In: MIGUEL, Luis Felipe; BIROLI, Flavia. Teoria política feminista: textos centrais. Vinhedo: Editora, 2013, p. 81-120.

GOFFMAN, Erving. Frame Analysis. An Essay on the Organization of Experience. Boston: Northeastern University Press, 1974.

HIGH-PIPPERT, Angela. A Million Moms, MADD Mothers, and Feminists: Media Coverage of Women Activists. In: CARILLI, Theresa; CAMPBELL, Jane 
(eds.). Women and media - diverse perspectives. University Press of American, 2005, p. 199-211.

hooks, bell. Homeplace: a site of resistance. In: - Yearning: race, gender, and cultural politics. South End Press: Boston, 1990, p. 41.50

LIND, Rebecca; SALO, Coleen. The framing of feminists and feminism in news and public affairs programs is U.S. electronic media. Journal of Communication, 2002, p. 211-228.

MENDES, Kaitlynn 'Feminism rules! Now, where's my swimsuit?' Reevaluating feminist discourse in print media 1968-2008. Media, Culture \& Society. 34(5), 2012, p. 554-570.

MENDES, Kaitlynn. Framing Feminism: News Coverage of the Women's Movement in British and American Newspapers, 1968-1982. Social Movement Studies, Vol. 10, No. 1, 2011a, p. 81-98.

MENDES, Kaitlynn. Reporting The Women's Movement. Feminist Media Studies, 11:4, 2011b, p. 483-498.

MENDES, Kaitlynn. Slutwalk, feminism and news. In: SILVA, K.; MENDES, K. Feminist erasures. Challenging Backlash Culture. Londres: Palgrave Macmillan, 2015, p. 219-234.

MENDONÇA, Ricardo Fabrino; SIMÕES, Paula. Enquadramento: Diferentes operacionalizações analíticas de um conceito. RBCS, Brasília, v. 27, n.79, 2012, p.117-235.

NORRIS, Pippa. Women Leaders Worldwide: A Splash of Color in the Photo Op. In: p. $149-165$.

NORTH, Louise. Rejecting the 'F-word'. How 'feminism' and 'feminists' are understood in the newsroom. Journalism. v.10 (6), 2009, p. 739-757.

OKIN, Susan. Justice, gender, and family. NY: Basic Books, 1989.

PATEMAN, Carol. O contrato sexual. Rio de Janeiro: Paz e Terra, 1993.

PINTO, Celi. Uma História do feminismo no Brasil. São Paulo: Fundação Perseu Abramo, 2003.

REESE, Stephen. The Framing Project: A Bridging Model for Media Research Revisited. Journal of Communication, v.57, n. 1, 2007, p. 148-154.

ROSS, Karen. Women, politics, media: uneasy relations in comparative perspectives. Hampton Press, 2002.a.

SARMENTO, Rayza. Midia, gênero e política: breve mapeamento de horizontes analíticos. Ação Midiática - Estudos em Comunicação, Sociedade e Cultura, Curitiba, v. 2, 2013, p. 1-15. 
SARMENTO, Rayza. Das sufragistas às ativistas 2.0: feminismo, mídia e politica no Brasil (1921a 2016). 2017. Tese de Doutorado. Universidade Federal de Minas Gerais, Belo Horizonte, 2017.

SARMENTO, Rayza Estudos feministas de mídia e politica: uma visão geral. BIB, São Paulo, v. 87, 2018. p. 181-202.

SHERIDAN, Susan et.al. Feminism in the news. In: HOLLOWS, Joanne; MOSELEY, Rachel. Feminism in popular culture. NY: Berg Publishers, 2006, p. 25-40.

SNOW, David. BENFORD, Robert. Master frames and Cycles of Protest. In: Morris, Al. et al. Frontiers in Social Movement Theory. New Haven: Yale University Press, 1992, p. 133-155.

VAN GORP, Baldwin. The constructionist approach to framing: bringing culture back in. Journal of Communication, v. 57, n.1, 2007, p. 60-78

VAN ZOONEN, Liesbet. The women's movement and the media: constructing a public identity. European Journal of Communication. v.7, 1992, p. 453476.

WALBY, Silvia. Theorizing patriarchy. Oxford: Blackwell, 1990.

YOUNG, Iris Marion. Justice and the Politics of Difference. Princeton: Princeton University Press, 1990. 